3 Mallampati SR. Bronchospasm during spinal anesthesia. Anesth Analg 1981; 60: 839-40.

4 Wang $C Y$, Ong GS. Severe bronchospasm during epidural anaesthesia. Anaesthesia 1993; 48: 514-5.

5 Gal TJ. Bronchospasm. In: Gravenstein N, Kirby R (Eds.). Complications in Anesthesiology, 2nd ed. Philadelphia: Lippincott-Raven, 1996: 99-210.

\section{Maintaining ventilation through the Montgomery $t$-tube}

The Montgomery T-tube was first introduced in $1980^{1}$ to be used in place of a standard tracheostomy tube for patients with tracheal defects. The problem of artificial ventilation through the $\mathrm{T}$-tube remains however. The previously described method of using a Fogarty catheter to obstruct the upper intraluminal limb of the T-tube is not suitable for long term ventilation. ${ }^{2}$ We describe a new method of ventilation through the T-tube using a customized armored tube.

Two adults with ventilatory dependency due to $\mathrm{Cl}$ quadriplegia and subglotic stenosis were referred to the Southport Spinal Injuries Unit for long term ventilation and rehabilitation one month following road traffic accidents. Both patients required silicone T-tube insertion subsequently. In preparation for this procedure both patients underwent diaphragmatic pacing to maintain breathing by electronic stimulation during the $\mathrm{T}$-tube insertion under total intravenous anesthesia.

A $5 \mathrm{~mm}$ I.D. arrnored tube, $(8 \mathrm{~mm}$ O.D.) with a standard $15 \mathrm{~mm}$ connector, and $10 \mathrm{~cm}$ long, had been ordered specially to fit a $14 \mathrm{~mm}$ I.D. T-tube (Boston Medical Products). After its insertion into the T-tube, the proximal end of the armored tube was engaged firmly into the outer limb of the T-tube to provide an air-tight seal (Figure). It was then possible to provide adequate pulmonary ventilation through the T-tube using a Puritan Bennett 2801 companion in the pressure control mode. In this way, an essential alternative mode of ventilation to diaphragm pacing was easily available without the need to remove the T-tube.

Whilst this method of ventilation can be used for anesthesia, an advantage for long terrn transtracheal ventilatory assistance is its ability to provide both adequate pulmonary ventilation and a translaryngeal airflow sufficient for speech.

\section{A. A. Al-Kaisy, ${ }^{\star}$ A P Kent, ${ }^{\dagger}$ J.W.H. Watt ${ }^{\dagger}$}

*Department of Anesthesia, The Toronto Hospital, \& tSpinal Injuries Centre, Southport and Formby NHS Trust Hospital, Southport, England.

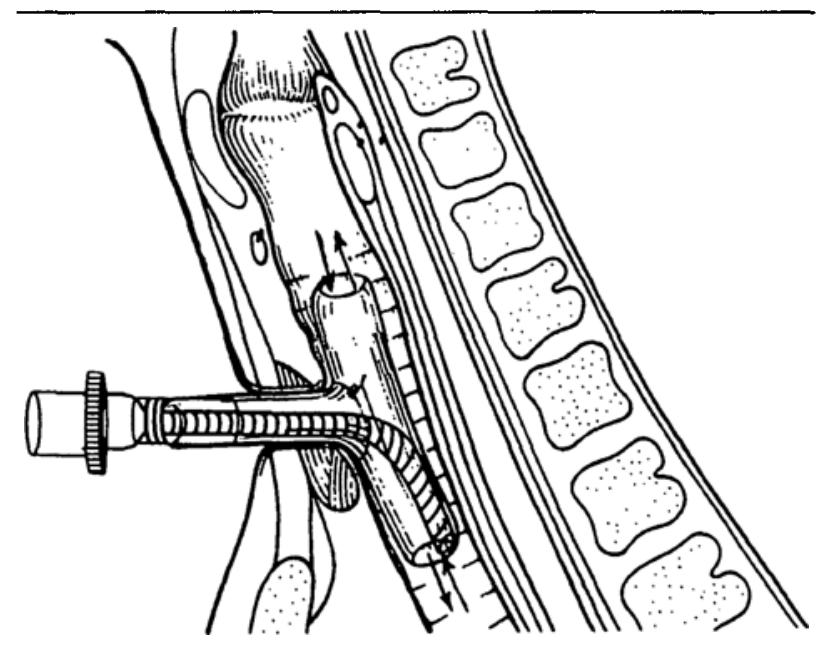

FIGURE A sagittal section showing the trachea with a Montgomery $t$-tube in situ and its removable inner armored tube for use with pressure control ventilation.

\section{REFEREN CES}

1 Montgomery WW. Silicone tracheal cannula. Ann Otol Rhinol Laryngol 1980; 89: 521-8.

2 Montgomery WW. Manual for care of Montgomery silicone tracheal T-tube Ann Otol Rhinol Laryngol 1980; 89 (Suppl): 1-8. 